\title{
Testamentos de José Luís Peixoto
}

\author{
LÍLIAN LOPONDO \\ Universidade Presbiteriana Mackenzie / Universidade de São Paulo
}

\begin{abstract}
RESUMO: O ROMANCE NENHUM OLHAR, DE AUTORIA DO PORTUGUÊS JOSÉ LUÍS PEIXOTO E VENCEDOR DO PRÊMIO SARAMAGO 2001, FOCALIZA A TRAJETÓRIA DE UM PEQUENO GRUPO DE PERSONAGENS DE UMA COMUNIDADE SEM NOME (ALENTEJO?). O TEXTO CONSTRÓI-SE MEDIANTE O PROCESSO DE DUPLICAÇÃO, QUE PERMITE CONSIDERAR O SEU PARADIGMA - A SAGRADA ESCRITURA - SOB NOVOS PRISMAS. ESTE TRABALHO TEM COMO OBJETIVO O ESTUDO DOS MECANISMOS POR MEIO DOS QUAIS SE EFETUA O DIÁLOGO COM O PROTOTEXTO NO ROMANCE, COM VISTAS AO EXAME DA TENSÃO COM O MODELO QUE LHE SERVE DE GUIA.
\end{abstract}

ABSTRACT: THE NOVEL NENHUM OLHAR, BY THE PORTUGUESE WRITER JOSÉ LUÍS PEIXOTO AND WINNER OF THE 2001 SARAMAGO AWARD, FOCUSES ON THE TRAJECTORY OF A SMALL GROUP OF CHARACTERS FROM A NAMELESS CITY (ALENTEJO?). THE TEXT IS BUILT ON THE BASIS OF THE DUPLICATION PROCESS WHICH PERMITS CONSIDERING ITS PARADIGM - THE HOLY SCRIPTURE - UNDER NEW PERSPECTIVES. THIS PAPER MAIN OBJECTIVE IS THE STUDY OF THE MECHANISMS ON WHICH INTERTEXTUALITY BETWEEN THE NOVEL AND ITS MODEL OCCURS, VIEWING THE EXAMINATION OF THE TENSION BETWEEN ITS COSMOVISION AND THE ONE FROM THE HOLY BIBLE.

PALAVRAS-CHAVE: INTERTEXTUALIDADE - TRÁGICO - ROMANCE CONTEMPORÂNEO KEY-WORDS: INTERTEXTUALITY - TRAGIC - CONTEMPORARY NOVEL 
romance Nenhum olhar, de José Luis Peixoto, tem a duplicação como traço constitutivo essencial. O Livro I, à semelhança das Sagradas Escrituras, é uma prefiguração do Livro II, no qual as personagens como que concretizam as "profecias" do primeiro. Há uma homologia entre os dois Livros em que o sem-sentido da existência subjaz como fio condutor.

O cenário, nas duas partes, mantém-se intacto: o monte das oliveiras; o bar do judas, ponto de encontro dos membros da comunidade; a estrada, por onde transitam as personagens; as casas, palco dos dramas de cada um; e a igreja, centro de profanização do sagrado, permanecem inalterados ao longo da narrativa. As personagens (re)vivem os mesmos conflitos, o que explica, inclusive, a retomada de seus nomes, por sua vez apoiados na alcunha de personagens bíblicas, e a presença dos gêmeos. Confirma-se, ainda, o desdobramento narrativo no título do romance, reiterado no epílogo:

O mundo acabou. E não ficou nada. Nem as certezas. Nem as sombras. Nem as cinzas. Nem os gestos. Nem as palavras. Nem o amor. Nem o lume. Nem o céu. Nem os caminhos. Nem o passado. Nem as idéias. Nem o fumo. O mundo acabou. E não ficou nada. Nenhum sorriso. Nenhum pensamento. Nenhuma esperança. Nenhum consolo. Nenhum olhar. (PEIXOTO, 2005: 191)

A última frase do excerto põe em evidência não só o universo claustrofóbico da aldeia (Alentejana?) - erguida em tempo de moto perpétuo, a ponto de conferir ao texto uma estrutura fechada, mergulhada em si mesma - mas também o recurso da multiplicação sobre o qual se alicerça. Os conectivos coordenativos aditivos $e$, nem (nenhum) - sempre os mesmos - repetidos anaforicamente, carregam, no bojo do processo de adição, o seu esvaziamento, intensificado mediante a epífora nada. Analogamente a outros momentos do texto, em que a repetição se efetua por intermédio da gradação, os substantivos abstratos e concretos, no plural ou no singular, que a uma primeira visada se equivalem, sofrem um processo de amplificação, apontando sempre para o idêntico/diverso Segundo Lausberg (1967: 166), "A conjunção, que sintaticamente pertencia ao último membro, alonga esse membro e permite assim a manutenção da lei dos membros crescentes" (grifo meu), relacionada ao "corpo da palavra" (nem... nem), que confere ao excerto um tom de ladainha, e com a sua intensidade semântica, cujo clímax se dá com a última frase. 
Se se levarem em conta as reflexões concernentes ao trecho acima, verificar-se-á que a estrutura do romance de José Luís Peixoto opõe-se radicalmente à das Escrituras Sagradas. Ao examinar as relações entre a Bíblia e a Literatura, em $O$ código dos códigos, Northrop Frye (2004: 206) ensina:

Já nos referimos antes à estrutura do Livro dos Juízes, onde uma série de estórias de heróis tribais se enquadra num mythos que se repete: o da apostasia e da restauração de Israel. Isto nos fornece uma estrutura narrativa que é, grosso modo, em forma de U: à apostasia se segue uma queda em desastre e cativeiro; a isto se segue o arrependimento, e por uma ascensão e liberação até um ponto que está mais ou menos ao nível do começo.

Acrescenta o estudioso que este modo de construção é retomado, literariamente, na comédia, em que "uma série de infelicidades e de incompreensões leva a ação a um ponto baixo e ameaçador; a partir daí uma reversão afortunada no enredo despacha a conclusão para um final feliz" (FRYE, 2004). Em lugar da euforia, própria do cômico, o romance em pauta permanece no âmbito disfórico: a forma da U cede espaço à forma em $\mathrm{L}$ - se a aproximação com a letra do alfabeto convier -, típica do trágico.

O leitor atento certamente porá em xeque estas considerações argumentando que, num dos núcleos dramáticos mais importantes da narrativa - o que coloca em evidência os irmãos Moisés e Elias -, a estrutura em L pode ser questionada: Moisés casa-se com a cozinheira, ambos têm uma filha e, juntamente com Elias, levam uma vida harmoniosa. Apresentem-se, pois, os gêmeos, unidos pelo dedo mindinho:

Os irmãos chamavam-se Moisés e Elias. Para quem estivesse diante deles, Moisés era o da esquerda, Elias o da direita. Por um evidente motivo, Moisés era destro e Elias era canhoto. Além desse pormenor, eram iguais em tudo. Mas, apesar de serem iguais em tudo, de se moverem com uma extraordinária coordenação e de ao olhar serem indistintos, havia uma diferença que os dividia ou que, se calhar, os unia ainda mais: Elias não falava. Ou melhor, falava, mas apenas ao ouvido de Moisés que, se fosse o caso, se apressava a dar voz às palavras sussurradas do irmão. Desde crianças que assim era. (PEIXOTO, 2005: 16) 
Conforme os diversos narradores a relatar a trajetória dos irmãos, à sua união de sobrevém a crise, deflagrada pela paixão de Moisés pela cozinheira. Em concordância com a reiteração e com o tom monocórdico das palavras finais da obra, observa-se, então, mais uma vez, a figura da gradação, agora a apontar a diferença de pontos-de-vista dele e do irmão. Tudo tem início com a cerimônia de casamento de José. Moisés a descreve, minuciosamente, quase que na íntegra, enfatizando a impressão que a cozinheira lhe causou: "Ela era uma mulher. E não ficou espantada com o caso de eu e o meu irmão estarmos pegados. E quase me sorriu uma vez. E quase me olhou nos olhos. Ela era uma mulher." (PEIXOTO, 2005: 37). Mais uma vez são utilizadas orações coordenadas assindéticas e sindéticas aditivas provocando - via polissíndeto - o efeito de repetição do igual e de acumulação do diferente. É reiterada, no trecho, a circularidade do romance.

Quanto a Elias, "pensava no casamento de José e pensava no irmão a derreter-se para a cozinheira nesse dia”. (PEIXOTO, 2005, grifo meu). O narrador em primeira pessoa cede lugar ao de terceira (como se sabe, Elias não fala, a não ser ao ouvido do irmão), a coordenação (pensava... e pensava) é substituída pela subordinação (a derreter-se pela coz̧inheira), em que a oração adjetiva explicativa implica a avaliação de Moisés por Elias. Desaparece, aqui, a amplificação gerada pela sonoridade, muda o ritmo narrativo e perde-se a intensidade semântica.

Estas diferenças de pontos-de-vista comprovam a apresentação dos irmãos efetuada pelo narrador que, mais tarde, sublinha:

Os seus olhares eram iguais, mas não viam o mesmo. Eram o mesmo olhar a ver duas coisas. Durante os meses em que / o velho Gabriel / estava parado, eram os irmãos que tomavam conta do lagar. Sempre juntos, sempre um ao lado do outro, envelheceram ao mesmo tempo: tinham a mesma curva nas costas, o mesmo andar pouco ligeiro e, sem que o soubesse, o mesmo número exato de cabelos brancos na cabeça. Já tinham passado muito mais de setenta anos da manhã de puro agosto em que, ao mesmo tempo, nasceram, rasgando a mãe por dentro à sua passagem. Contavam os mais velhos, que tinham ouvido dos seus pais, que, assim que lhes cortaram os cordões umbilicais, a mãe os olhou e viu ainda que eram siameses. (PEIXOTO, 2005: 15, grifo meu) 
Casados Moisés e a cozinheira, restabelece-se a harmonia entre os três, a tal ponto que o leitor é instado a pensar que, com as bodas, caminha o romance na direção ascendente referida por Frye. Porém, a placidez doméstica promove uma perigosa aproximação entre os irmãos e, lentamente, mina as diferenças entre eles. Frente às esculturas culinárias concebidas pela cozinheira, concordam em dispor dos parcos recursos financeiros para custear os arroubos gastronômicos da esposa de Moisés: a perplexidade dá lugar à concordância. E uma noite, "Moisés comeu a pequena mulher, esculpida em peito de frango, e Elias comeu o berço e o menino, esculpido de uma perna de frango. Nessa noite, ao adormecerem os três, a cozinheira fez cara de caso e disse vais ser pai." (PEIXOTO, 2005: 47, grifo meu). ${ }^{1}$ A partir de então, e até a sua morte, esvaem-se os traços de personalidade que os distinguiam, como se, agora, sim, fossem iguais em tudo. Contrariando todas as expectativas, instala-se a crise entre os irmãos.

No caso de José, a duplicação ocorre em outro plano. O protagonista do Livro I tem a sua trajetória marcada pela dúvida gerada pelo estupro de sua mulher pelo gigante: de quem é o filho concebido por ela? O do Livro II, filho de José e da mulher de José, apaixonado pela filha de Moisés com a cozinheira, não se decide a manifestar nem a concretizar seu amor por ela. $\mathrm{O}$ primeiro suicida-se e o segundo amarga o silêncio e a solidão. Não há saída para o homem peixoteano, cuja dor se duplica, reduplica e multiplica em sua aniquilação.

Tal afastamento do modelo bíblico desvela-se, também, mediante o principal mecanismo de que se utiliza o Autor para a obtenção da intertextualidade: a citação. Segundo Patrick Pavis (1999: 48) "citar, efetivamente, é retirar um fragmento de texto e inseri-lo num tecido estranho." Continua: "A citação está ligada ao mesmo tempo ao seu contexto original, e ao texto que a recebe. O 'atrito' desses dois discursos produz um efeito de estranhamento" (grifo do autor). Assim sendo, a citação "pode confirmar ou alterar o sentido do texto citado" (BARROS \& FIORIN, 2003: 30).

1 Não é demais salientar que não só os alimentos preparados pela cozinheira como também as refeições partilhadas pelos irmãos apresentam alta carga simbólica. No que diz respeito ao excerto citado, observa-se a forte referência aos mitos de Dioniso e de Cronos, rebaixados e recontextualizados no Alentejo peixoteano. Além disso, há que observar que tanto a cozinheira quanto Moisés já ultrapassaram os setenta anos. A gravidez soma vida e morte, situando o casal e Elias no limiar da existência. 
Salta à vista, é preciso reiterar, o aproveitamento dos nomes das personagens que, sem exceção, remetem a figuras de grande importância nas Sagradas Escrituras: José, esposo de Maria e suposto pai de Jesus; Moisés e Elias, o patriarca e o profeta; Gabriel e Rafael, anjos do Senhor; Salomão, o rei, sábio, e, por fim, Judas, o delator de Jesus Cristo. Há, ainda, duas figuras emblemáticas: o gigante que, em certa medida, desempenha o papel designado ao Espírito Santo, e o demônio, que aparece tanto no hipotexto quanto no intertexto como o tentador.

Além do mais, o monte das oliveiras é o espaço central da narrativa, o local em que se passa grande parte dos acontecimentos, da mesma maneira que na Bíblia esse monte é citado freqüentemente, ora como um lugar de repouso para Jesus, ora como local de importantes decisões que ele toma ao lado de seus apóstolos.

Dessa forma, personagens e espaço citados em Nenhum olhar fazem parte de uma episteme imediatamente reconhecível - as Sagradas Escrituras - mas recontextualizados, com sentido invertido, potencializador do baixo, do grotesco, sustentado sobre sua própria lógica: a do trágico, ou seja, a do homem como refém de um universo fragmentário, de impossível apreensão. Além disso, é preciso considerar, com Bornheim (1969: 17) que "Deve haver algo no homem que possibilite a vivência trágica. Poderíamos chamar de finitude, de contingência, de imperfeição ou ainda de limitação o elemento possibilitador do trágico (BORNHEIM, 1969: 72). A relação entre essas dimensões deixa de ser baseada na verticalidade e instaura a horizontalidade, pois " $\mathrm{O}$ traço marcante do realismo grotesco é a transferência ao plano material e corporal, ao da terra e do corpo, na sua indissolúvel unidade, de tudo que é elevado, espiritual, ideal e abstrato" (BAKHTIN, 1987: 17). A lógica do trágico, aqui, se escora no rebaixamento ao sublinhar o lado corporal e material do homem, ou seja, suas imperfeições, suas limitações e sua finitude, que desembocam na dor do mundo.

Em Nenhum olhar, no Livro I, há uma família completa, isto é, constituída por José, sua mulher e seu filho, que remete à Sagrada Família, formada por José, Maria e Jesus. No Livro II, porém, José, filho de José, é solteiro e sua família é composta pela mãe e pelo primo Salomão. No Livro I, José desempenha o papel de pai e no Livro II ele é tão somente o filho. Nota-se, porém, que no Livro I o pai de José, embora vivo, ausenta-se da realidade: 
O pai de José não voltou ao monte. Deixou de falar e só comia a sopa que lhe davam na boca. A irmã de José vivia na vila, era casada com o ferrador, e foi ela que recolheu o pai. Vejam-me só esta miséria, dizia ela às vizinhas. O pai ficava todo o dia sentado num banco no quintal, diante da capoeira, a olhar para lado nenhum, como um cego. (PEIXOTO, 2005: 28)

No Livro II, o pai de José se suicida quando este ainda é bebê:

José era filho de José. Tinha o mesmo nome do pai, e dele sabia as poucas respostas que lhe tinham dado às poucas perguntas que fizera, sabia que era igual a ele, porque era o que o velho Gabriel sempre lhe dissera desde criança. És igualzinho ao teu pai. Nunca ninguém tivera coragem de contar a José a forma como o pai morrera, mas José tinha aprendido com o luto carregado da mãe que esse não era um assunto do qual se falasse. (PEIXOTO, 2005: 102)

Em oposição à Bíblia, em que José, representante humano da figura paterna na Sagrada Família, é presente e protetor assim como o pai divino é onipotente e onipresente, em Nenhum olhar a ausência paterna reforça o rebaixamento que permeia o texto. Quanto ao filho, é criada uma oposição entre o José do Livro I e o filho sagrado da Bíblia, na medida em que a morte do primeiro significa o fim enquanto a do segundo anuncia uma nova vida. Em Lucas 23, 28 o filho sagrado, a caminho do calvário, afirma: "Filhas de Jerusalém, não choreis por mim; chorai, antes, por vós mesmas e por vossos filhos! Pois, eis que virão dias em que se dirá: felizes as estéreis, as entranhas que não conceberam e os seios que não amamentaram!"

Em Nenhum olhar, José, momentos antes de se enforcar, anuncia:

Mulher, filho, pai, mãe, irmã, não chorem por mim. Ainda há as searas para as crianças. Ainda há as crianças. Guardem as lágrimas para um dia de mais alta nomeada. Guardem as lágrimas para o dia em que morrerem as searas nos olhos das crianças, para o dia em que morrerem as crianças. (PEIXOTO, 2005: 97)

Tanto no modelo quanto no intertexto, trata-se de um pedido e de um aviso. O pedido: não chorar por aquele que parte; o aviso: chegará a hora em 
que terão outros motivos para chorar. Nesse sentido, dialogam em convergência. Porém, o avesso da concordância logo se revela porque o conteúdo de cada um desdiz o do outro. O texto bíblico menciona a esterilidade como valor positivo em vista do futuro; a narrativa trata da morte da esperança figurativizada na morte das searas nos olhos das crianças e na própria morte das crianças.

Além disso, a morte do filho sagrado foi prevista: "Eis, porém, que a mão do que me trai está comigo, sobre a mesa. O Filho do Homem vai, segundo o que foi determinado, mas ai daquele homem por quem ele for entregue" (Lucas 22: 21) e tem um propósito de salvação: "É agora o julgamento deste mundo, agora o príncipe deste mundo será lançado abaixo; e, quando eu for elevado da terra, atrairei todos a mim" (João 12: 31), em oposição ao suicídio de José que, no romance, não significa nada, não modifica a ordem do mundo: "Hoje, morro eu. E eu morrer não é nada na ordem implacável do mundo" (PEIXOTO, 2005: 97). Decide matar-se, vai até uma árvore e se enforca. Não há nada de grandioso nisso, nada de heróico. Sua morte não tem um propósito ulterior nem ninguém a presencia.

Verifica-se, também, que, em João 14:2, Jesus dirige a palavra aos seus discípulos e anuncia que um dia eles estarão ao seu lado e terão a vida eterna:

Na casa de meu Pai há muitas moradas. Se não fosse assim, eu vos teria dito, pois vou preparar-vos um lugar, e quando for e vos tiver preparado o lugar, virei novamente e vos levarei comigo, a fim de que, onde eu estiver, estejais vós também.

No intertexto, em contrapartida, o tom é oposto:

E, onde estiver, não poderei tocar-te, como nunca pude. E essa angústia será maior, porque nunca mais poderei ver-te, nunca mais poderei ouvir o teu silêncio e toda a esperança que um dia tive será nula. Morto, assistirei ao negro absoluto que nenhum homem pode suportar em vida. Nenhuma luz, nenhuma luz. E é para isto que tenho de caminhar. E poucos metros me separam da lonjura imensa desse sítio. Sofrer será a continuação de sofrer. A vontade que nunca tive, não terei. E os meus passos já não são meus, nunca foram. Tudo é último. Os campos resistiram um dia mais, e amanhã não existe. (PEIXOTO, 2005: 96) 
O romance aparta-se da vida espiritual e limita a vida humana à sua existência material, dessacralizando-a. Contradiz as idéias de futuro e retorno expressas no fragmento bíblico e o presente se torna a única dimensão temporal. A ressurreição do filho sagrado é subvertida e rebaixada tanto no Livro I quanto no II, porque ambos reiteram a idéia da finitude humana:

José e a sua mãe, Salomão e a sua mulher, o demônio, a cozinheira viúva, todos morreram, no meio de todos os homens e mulheres que morreram, como pontinhos de uma multidão gigante a morrer no mesmo instante sem poder entender que morria e que morria tudo. Todos desapareceram e não deixaram nada, e não deixaram sequer o pequeno nada que existe dentro do nada que existe dentro do nada. (PEIXOTO, 2005: 191)

Em lugar da transcendência salvadora que permeia o discurso bíblico, há a imanência destruidora da contemporaneidade, a realidade material, com tudo o que tem de efêmero, uma vez que "sempre se está irrecuperavelmente no mundo, que é organizado, se o é, em estruturas locais e temporais que operam sem referência a causas secretas ou últimas" (CONNOR, 1993: 98); "o local, o limitado, o provisório" (HUTCHEON, 1991: 68) e suas múltiplas verdades têm como fim último a dor do mundo à qual, no universo do jovem Autor português, ninguém está imune.

Enquanto o texto bíblico se duplica voltado para o futuro e a divisão dos testamentos em "antigo" e "novo" sugere a renovação, em Nenhum olhar, o futuro não existe: "Sou pouco, sou insignificante, sou um passado de desencontros e enganos, sou o gesto de olhar este céu, sou futuro nenhum e esta certeza" (PEIXOTO, 2005: 187). Há, no texto, um retorno cíclico que se verifica não só pela duplicação de José no Livro II como, por exemplo, na repetição de discursos do Livro I no Livro II. José afirma, no Livro I: "Penso: se o castigo que me condena se fechar em mim, se aceitar o castigo que chega e o guardar, se o conseguir segurar cá dentro, talvez não tenha de suportar novos julgamentos, talvez possa descansar" (PEIXOTO, 2005: 11). E, de forma idêntica, no Livro II: "Penso: se o castigo que me condena se fechar em mim, se aceitar o castigo que chega e o guardar, se o conseguir segurar cá dentro, talvez não tenha de suportar novos julgamentos, talvez possa descansar" (PEIXOTO, 2005: 142). Os trinta anos que separam os dois Josés não impedem que am- 
bos sofram e pensem da mesma maneira e expressem sua dor identicamente, palavra por palavra, reforçando o tom de ladainha da narrativa.

Ademais, se nas Sagradas Escrituras o processo de duplicação (Antigo Testamento e Novo Testamento) se constrói por meio da coordenação, em Nenbum olhar (Livro I e Livro II) ocorre por meio da subordinação. Na Bíblia esse recurso fundamenta-se na independência porque, ainda que as profecias do Antigo Testamento se concretizem no Novo Testamento, ambos podem ser tomados separadamente. Na narrativa, no entanto, os Livros I e II são interdependentes. À idéia de liberdade expressa nas Sagradas Escrituras contrapõe-se a de ligação contratual essencial entre as duas partes do romance.

Estrutura em L, bipartição, gradação, anáfora, citação, são os expedientes de que se vale José Luís Peixoto para - como ele próprio o afirma - compor o seu Alentejo, árido, desértico, cujo habitante é o indivíduo do limiar, do aquém/além, do sim/não, do sempre/nunca... do nada/nada.

$$
* * *
$$

\section{Referências Bibliográficas}

BAKHTIN, Mikhail. A cultura popular na Idade Média e no Renascimento. São Paulo: Hucitec, 1987.

BARROS, Diana L. P.; FIORIN, José Luiz (Org.). Dialogismo, polifonia, intertextualidade. São Paulo: Edusp, 2003.

Bíblia de Jerusalém. São Paulo: Paulus, 2004.

BORNHEIM, Gerd. A. O sentido e a máscara. São Paulo: Perspectiva, 1969.

CONNOR, Steven. Cultura pós-moderna. São Paulo: Loyola, 1993.

FRYE, Northrop. O código dos códigos. São Paulo: Boitempo, 2004.

LAUSBERG, Heinrich. Elementos de retórica literária. Lisboa: Calouste Gulbenkian, 1967.

HUTCHEON, Linda. Poética do pós-modernismo. Rio de Janeiro: Imago, 1991.

PEIXOTO, José Luís. Nenhum olhar. Rio de Janeiro: Agir, 2005. 